\title{
O jeito brasileiro de publicar em estudos organizacionais
}

\author{
Barbara Hemais - Prof ${ }^{a}$ Dept $^{0}$ de Letras da PUC-RIO \\ Sylvia Constant Vergara - Prof ${ }^{\text {a }}$ da EBAP/FGV
}

\begin{abstract}
Trata-se de um estudo acerca das citações na produção científica brasileira sobre organizações, com foco nos traços lingüísticos. Citações são a característica textual que ajuda a mostrar como uma produção científica alinha-se a um certo ramo ou a uma certa corrente do conhecimento. Por outro lado, a análise lingüística amplia a compreensão das escolhas feitas pelos autores, como também o condicionamento cultural ao qual estão sujeitos. Contemplando uma amostra de 25 trabalhos dos Anais do ENANPAD 99 na área de Organizações, foram examinadas, em cada trabalho, duas dimensões da citação: a forma do verbo de reportagem e a integração do nome do autor citado. As conclusões sugerem que os autores brasileiros preferem não polemizar, parecem depender de poucas fontes de informações, bem como dão mais destaque ao que é produzido fora do Brasil, especialmente nos Estados Unidos.
\end{abstract}

\section{Introdução}

Em toda pesquisa científica, a escolha do problema a ser investigado revela questões que são consideradas centrais pelos pesquisadores. No entanto, essas questões podem ter origem ou resposta em linhas de investigação que têm sua base de informações em uma cultura acadêmica alheia e que não retrata os valores locais de onde a organização enfocada na pesquisa está inserida. Não é diferente nos estudos organizacionais. No caso brasileiro, há predominância da cultura anglo-americana. No entanto, vários pesquisadores têm questionado a adequação de aplicação de informações geradas em outras culturas e têm chamado a atenção para a necessidade de o enfoque, os objetivos e a base de informações da pesquisa estarem afinados com a sociedade brasileira (Bertero e Keinert,1994; Lima, 1999; Vergara e Carvalho,1995; Vergara e Pinto, 2000).

Como acontece em outras áreas acadêmicas, os trabalhos de pesquisa na área de organizações reportam-se a conhecimento já existente. As referências e as citações dos autores revelam suas preocupações com o conteúdo da pesquisa e com a metodologia, bem como revelam sua formação acadêmica. Além do mais, por meio de citações os autores dão indícios de sua experiência anterior com textos. Ou seja, eles utilizam informações obtidas em outros textos com os quais mantêm um diálogo. Tais textos podem fornecer o arcabouço teórico que sustenta as proposições do autor, suas hipóteses e métodos que defende ou critica.

No caso de estudos organizacionais no Brasil, o diálogo entre autor e textos envolve uma certa dominância da pesquisa anglo-americana, como mencionado. Esse diálogo realiza-se, em parte, por meio de citações em artigos de pesquisa, as quais demonstram sinais da reprodução de conceitos e formulações que foram concebidos, particularmente, no contexto anglo-americano. Assim, os autores revelam um certo condicionamento a padrões culturais que não lhes pertencem e nem fazem parte de sua realidade local. Considerou-se, então, 
relevante examinar a forma que autores brasileiros tendem a preferir para citar outros autores. Deve-se notar que mencionar, predominantemente, autores de outras culturas não é um fenômeno tipicamente brasileiro. Pesquisa de Engwall (1996), examinando textos franceses nessa área, demonstrou que nos artigos estudados também a influência americana se faz sentir fortemente.

Se o presente estudo, inicialmente, objetivou examinar a produção de estudos organizacionais no Brasil, para verificar até que ponto há dependência de referências estrangeiras, há importação de estilos e conclusões e, portanto, há o condicionamento a padrões culturais alheios, no entanto, o estudo acabou por permitiu ir além, revelando o jeito brasileiro de publicar.

\section{O Estudo}

O uso de citações em trabalhos escritos por autores brasileiros foi o enfoque da pesquisa de Vergara e Carvalho (1995), Carvalho e Vergara (1996) e Vergara e Pinto (2000) na área de estudos organizacionais. As citações estavam abrigadas em artigos publicados na Revista de Administração de Empresas, Revista de Administração Pública, Revista da Universidade de São Paulo e nos Anais do ENANPAD, em um período de dez anos. A análise das citações revelou, entre outros resultados, que autores estrangeiros representam quase $70 \%$ dos autores citados nos artigos e desses autores estrangeiros, mais de 60\% são americanos. As outras referências estrangeiras são, predominantemente, de autores da França, Inglaterra, Alemanha e Canadá. Nos mesmos estudos foram feitas entrevistas e aplicados questionários a autores brasileiros cujos artigos foram analisados, com a finalidade de verificar o que os motivou ao uso de citações nas suas várias formas e de registrar como eles explicaram suas escolhas. Para a maioria dos autores entrevistados, a predominância de citações estrangeiras deve-se à maior variedade de fontes estrangeiras e à inércia dos pesquisadores brasileiros. Os estudos concluíram que os autores brasileiros que estudam organizações, por dependerem fortemente das informações de autores estrangeiros, são condicionados por culturas alheias no processo de criar textos.

Esta conclusão é corroborada pela crítica feita por pesquisadores brasileiros sobre a qualidade da pesquisa no Brasil. Um problema que foi identificado é que, em contraste com a riqueza de informações que cresceu por meio das intensas pesquisas americanas, há pouca pesquisa feita no Brasil sobre empresas; como resultado, pouco é conhecido sobre elas (Bethlem, 1989). Da própria amostra que serve para a presente pesquisa surge uma perspectiva crítica sobre a questão. Bernardes (1999), ao reconhecer limitações em sua pesquisa, chama a atenção para o fato de que a literatura que embasa seu trabalho é anglo-saxã e é carregada de um viés cultural. Lima (1999) vai além, defendendo uma conscientização sobre as limitações da pesquisa no Brasil, e resumindo as preocupações expressas por vários pesquisadores brasileiros. Lima observa que os artigos de autores do ENANPAD seguem um foco prescritivo (de um modelo importado) que não lhes permite levar em consideração as peculiaridades das organizações no Brasil e que impedem esses pesquisadores de construir um conhecimento científico que reflita a realidade local. Ainda, autores brasileiros, seguindo conceitos oriundos principalmente dos Estados Unidos, não se concentram na aplicação de soluções para situações reais de gerentes e administradores. Lima também cita Vergara e Carvalho Jr (1995), que identificam um debate acadêmico sobre o problema da pesquisa na área. Há uma tendência a pensar ser este fato um sinal de dominação. Esta conclusão é 
corroborada pela crítica feita por pesquisadores brasileiros sobre a qualidade da pesquisa no Brasil (Bertero, Caldas e Wood Jr., 1999).

Partindo da linha de investigação seguida por Vergara e Carvalho (1995) e Vergara e Pinto (2000), o presente trabalho procura uma análise mais detida nos traços lingüísticos das citações, em uma outra amostra de trabalhos referentes a estudos organizacionais. A análise lingüística busca ampliar a compreensão não somente das escolhas feitas pelos autores, como também o condicionamento da produção de informação nessa área de estudo.

A amostra desse trabalho é constituída por 25 trabalhos dos Anais do ENANPAD 99. Em cada trabalho foram examinadas duas dimensões de cada uma das citações, a saber: a integração do nome do autor citado e a forma do verbo de reportagem. Essas dimensões, que são explicadas na seção seguinte, fazem parte da análise feita por Swales (1990), abordando o texto acadêmico por meio de uma perspectiva retórica. Além disso, as opções do verbo léxico foram examinadas e essa dimensão também é explicada em seguida.

A pesquisa realizada configura-se como exploratória, não somente pelo número de artigos analisados, como também pela própria natureza do estudo: intertextualidade de trabalhos em estudos organizacionais. 


\section{Análise das citações}

Citações são, na metáfora de Cronin (1981:16), "rastros congelados no cenário dos avanços acadêmicos, rastros esses que testemunham a passagem de idéias". Assim, as citações estão fortemente relacionadas à informação que o escritor/autor retira dos textos científicos. Um artigo relaciona-se com outros textos e por meio dessa relação conecta-se com um "ramo de conhecimento específico" em alguma área da pesquisa científica (Amsterdamska e Leydesdorff, 1989:451). Citações são a característica textual que ajuda a mostrar como um artigo de pesquisa se encaixa em um certo ramo ou em uma certa corrente do conhecimento.

Seguindo a análise de Swales (1990:148), a citação especifica quem disse ou fez o quê e fornece um sinal da posição do escritor face ao que foi dito ou feito. Uma das características das citações é o uso de formas integral e não-integral, ou seja, a estrutura formal da oração na qual a citação está localizada. Na forma integral, o autor citado é apresentado como elemento da oração principal. Por exemplo: "Justis, Olsen and Chan (1993) apoiam esta idéia". Por outro lado, na forma não-integral o autor aparece em parênteses. Por exemplo: "esta análise reproduz a cópia da realidade (Reed, 1997)". Ou aparece em alguma outra forma de citação, como o sobre-escrito. O importante nessa distinção é que a forma da citação focaliza os pesquisadores (forma integral) ou a atividade de pesquisa (forma não-integral).

Para fins do presente estudo, essa distinção possibilita uma identificação das escolhas feitas por autores brasileiros em termos de formas de citações. Assim, examinando-se a forma integral, pode-se chegar a conclusões quanto à tendência dos pesquisadores brasileiros de se basear no que outros pesquisadores, tanto não-brasileiros quanto brasileiros, dizem ou fazem. Examinando-se a forma não-integral, pode-se também observar até que ponto a informação produzida é enfatizada.

Outra característica das citações é o uso do verbo de reportagem, uma vez que o verbo é um indicador de como interpretar a citação. Por exemplo: Fulano "sugere"..., Um experimento "realizado" ..., Uma posição "defendida" .... Escritores, por outro lado, podem escolher não incluir o verbo de reportagem e, neste caso, eles se abstêm de revelar como vêem a informação que estão apresentando. Como será detalhado adiante, verbos de reportagem expressam o relacionamento que o escritor estabelece com a informação e com o pesquisador citado. Em outros termos, os verbos mostram as escolhas do escritor para relacionar outro autor com aquilo que ele disse ou fez. Se as citações permitem observar o que Cronin (1981) chama de "a passagem de idéias", o verbo de reportagem mostra como essas idéias são registradas pelos autores. 


\section{Análise de citações em artigos referentes a estudos organizacionais}

$\mathrm{Na}$ seção anterior, destacamos a abordagem usada para uma análise textual dos artigos da amostra. Exemplos de duas características das citações são dadas abaixo, provenientes de alguns dos artigos analisados neste trabalho:

(a) Integral + Reportagem: "Kim (1993) apresenta uma abordagem . . ."

(b) Integral + Não-reportagem: "Segundo Sievers (1994: 159): . . “

(c) Não-integral + Não-reportagem: "O interesse por tipos ideais é crescente (Alvesson, 1990)".

(d) Não-integral + Reportagem: "Defende-se a necessidade de as empresas tornarem-se mais flexíveis e ágeis (Romeiro, 1996)"

A distinção entre integral e não-integral pode ser observada nesses exemplos. No exemplo (a) Kim é o autor citado e aparece na estrutura principal da oração; da mesma forma, no exemplo (b) o autor Sievers é um elemento da estrutura da oração. Esses autores estão localizados em citações integrais. Em contraste, em (c) e (d) os nomes dos autores estão apresentados dentro de parênteses, caracterizando casos de citações não-integrais.

Os padrões de utilização de verbo de reportagem estão também exemplificados nas citações. O verbo "apresenta" em (a) e "defende-se" em (d) são evidências de como os escritores escolhem a apresentação de sua informação e o trabalho dos autores citados. Nos exemplos (b) e (c), os escritores se abstêm de expressar suas visões ou qualquer grau de comprometimento com o que é citado.

\section{Duas dimensões das citações}

$\mathrm{Na}$ análise das citações dos artigos referentes a estudos organizacionais, as características integral/não-integral e reportagem/não-reportagem mostram o padrão exposto na Tabela 1. 
Tabela 1 -Tipos de citação encontrados na amostra

\begin{tabular}{|l|l|l|}
\hline \multicolumn{1}{|c|}{ Tipos de citação } & \multicolumn{1}{|c|}{$\begin{array}{c}\text { Número } \\
\text { absoluto }\end{array}$} & \multicolumn{1}{c|}{$\%$} \\
\hline Integral & 443 & $57 \%$ \\
\hline Não-integral & 332 & $43 \%$ \\
\hline & 295 & $38 \%$ \\
\hline Reportagem & 480 & $62 \%$ \\
\hline Não-reportagem & & \\
\hline
\end{tabular}

Em termos de apresentação da pesquisa e do pesquisador, as citações nesses artigos não são balanceadas, com $57 \%$ sendo integral e $43 \%$ não-integral. Não há, entretanto, um padrão regular de ocorrência nos artigos examinados. Alguns artigos têm um número bastante grande de citações integrais, enquanto outros apresentam citações não-integrais em número maior. Em um artigo, por exemplo, não existe qualquer citação não-integral e em outro citações não-integrais aparecem duas vezes mais do que as integrais. Entretanto, a contagem geral mostra uma preferência levemente maior por enfatizar o pesquisador citado, em vez de conceitos, teorias, métodos e descobertas das suas pesquisas.

Um ponto interessante é que o autor citado pode ser ativo em pesquisa no Brasil ou no exterior. Neste trabalho, argumenta-se que o prestígio ou a influência do pesquisador pode ser observado por meio da forma como a oração está organizada na citação. Para descobrir a quantidade de autores brasileiros e estrangeiros citados, eles foram separados por nacionalidade e contados nas citações integrais. Nos 443 casos de citações integrais, os autores brasileiros são destacados em cerca de $30 \%$ das citações, enquanto que os estrangeiros, notadamente os anglo-americanos são destacados em cerca de 70\%. Observa-se que as citações não-integrais representam $43 \%$ da amostra analisada. Mesmo essas citações, que destacam atividades de pesquisa em andamento, são em sua maioria de instituições estrangeiras, principalmente anglo-americanas. Outro ponto a ser destacado é que, quando autores brasileiros fazem uma auto-citação, eles usam quase que exclusivamente a citação na forma não-integral, talvez com o objetivo de chamar menos atenção para seu próprio trabalho de pesquisa. Nosso argumento é de que esses autores dão mais ênfase a pesquisadores dos Estados Unidos e até da Europa, do que aos brasileiros.

Uma outra tendência observada em alguns artigos é o grande número de citações a um pesquisador em especial, e uma ou duas citações a diversos pesquisadores. Mais precisamente, observou-se, após uma rápida análise preliminar, que, em metade dos artigos, os autores citam um ou dois pesquisadores até 12 vezes ao longo do texto. Mesmo considerando-se que o número de citações por texto varia de 8 até 60, e que em cada texto um número razoável de pesquisadores é citado, verificou-se uma certa dependência de poucas fontes. Para ilustrar, em quatro textos um autor é citado sete vezes, em dois textos um autor é citado nove vezes, em outro texto um autor é citado 10 vezes e em outro ainda, um autor é 
citado 12 vezes. Verificou-se, também, em um outro texto, que são usadas cinco páginas das 15 apresentadas, para discutir uma só fonte de literatura. Em alguns trabalhos, duas fontes fazem parte dessa dependência. Por exemplo: no trabalho com 12 citações a um só autor, há mais 10 citações a um outro autor. Além disso, em trabalhos com menos citações o embasamento mostra-se ainda mais limitado. Por exemplo: em um desses textos, $40 \%$ das citações são a um autor e $30 \%$ a um segundo autor. Deve ser mencionado, ainda, o caso de um texto no qual a grande maioria das citações é dos próprios autores do trabalho, ou seja, nesse texto os autores travam um diálogo com eles mesmos e com sua própria obra anterior. Essa dependência de um único autor (ou dois) inclui tanto aqueles brasileiros quanto os nãobrasileiros, mas o que é de notar é que os escritores dos artigos aqui privilegiados parecem depender fortemente de fontes limitadas de informação.

O uso ou não de verbos de reportagem mostra um forte padrão de preferências. Há uma tendência marcante entre os autores de fazerem citação sem usar verbo de reportagem, uma vez que $62 \%$ das citações não os utilizam. Isto indica que os autores brasileiros alvo do presente estudo preferem não explicitar sua opinião sobre quem ou o que está sendo citado. As escolhas de verbos de reportagem são também significativas, o que é explicado na próxima seção.

\section{Escolhas de verbos de reportagem}

De uma forma geral, quando autores usam verbos de reportagem, eles pretendem mostrar explicitamente como gostariam de apresentar a informação citada. Por meio da escolha do verbo léxico, os autores têm à sua disposição uma grande variedade de formas para mostrar suas visões sobre o status da informação.

Este trabalho adota o modelo de Thomas e Hawes (1994) sobre funções de verbos nas citações em artigos constantes de periódicos de medicina. Comparações com artigos médicos podem ter limitações, uma vez que o estudo mencionado não propôs levantar questões sobre intertextualidade em relação a escritores que se referem a autores pertencentes a uma comunidade acadêmica dominante (no caso, anglo-americana). Ainda, os verbos no presente estudo foram traduzidos literalmente, sem levar-se em consideração nuances de forma semântica ou uso pragmático. Acresce o fato de que deve haver uma motivação disciplinar para esses padrões divergentes, o que foge, porém, ao escopo do presente trabalho. Apesar dessas limitações e sem buscar fazer comparações, as categorias de Thomas e Hawes são úteis para a análise da amostra. As categorias identificadas no modelo permitem uma análise de dois aspectos do trabalho acadêmico que são de grande interesse para o presente estudo: o próprio processo de pesquisa e o discurso sobre a pesquisa.

O modelo de Thomas e Hawes mostra que os verbos de reportagem tomam funções que revelam a fase da atividade da pesquisa, ou seja, se o autor está conduzindo a pesquisa, escrevendo sobre ela ou externando uma percepção. Assim, os autores dividem os verbos das citações em três categorias, a saber:

- "Mundo Real/Experimento", que é relacionada ao processo da realização da pesquisa e inclui as sub-categorias de "Achados da Pesquisa" (por exemplo: "Logan et al. mostram"; "Alvritzer (1996) procura demonstrar na sua crítica") e "Verbos de Procedimento" (por exemplo: "o modelo desenvolvido por Hackman \& Oldham"; "adaptada, testada e validada por Moraes \& Kilimnik"). 
- "Verbos de Discurso", que inclui verbos que os autores usam para expressar posições em relação à pesquisa e às contribuições de outros pesquisadores (por exemplo: "modelo dos valores organizacionais, proposto por Tamayo"; "como coloca Fernandes"; "opondo-se a essa visão"). Os Verbos de Discurso incluem as seguintes sub-categorias: "Restrição", "Proposta"e "Certeza". Esta última subdivide-se em "Informe/Relato" e "Argumento".

- A categoria final é chamada "Cognição" (por exemplo: "Fayol (1990) percebeu a organização"; "o uso de tecnologias [...] é considerado altamente útil”).

Nos artigos de estudos organizacionais, aqui analisados, há uma grande concentração de verbos que encaixam-se nas categorias relacionadas com o andamento da pesquisa e ao discurso sobre a pesquisa, como mostrado na Tabela 2.

Tabela 2- Verbos de reportagem nos artigos de ENANPAD 99

\begin{tabular}{|l|c|c|c|c|c|c|c|c|}
\hline & \multicolumn{2}{|c|}{$\begin{array}{c}\text { Mundo } \\
\text { Real/Experimento }\end{array}$} & \multicolumn{2}{c|}{ Discurso } & \multicolumn{2}{c|}{ Cognição } & \multicolumn{2}{c|}{ TOTAIS } \\
\cline { 2 - 9 } & $\mathrm{N}^{\mathrm{o}}$ abs. & $\%$ & $\mathrm{~N}^{\mathrm{o}}$ abs. & $\%$ & $\mathrm{~N}^{\mathrm{o}}$ abs. & $\%$ & $\mathrm{~N}^{\mathrm{o}}$ abs. & $\%$ \\
\hline Verbos & 51 & 47 & 46 & 42 & 12 & 11 & 109 & 100 \\
\hline Ocorrências & 108 & 38 & 156 & 54 & 26 & 9 & 290 & 100 \\
\hline
\end{tabular}

Nos artigos alvo do presente estudo, há um uso balanceado de verbos que representam o Mundo Real e o Discurso, uma vez que $47 \%$ dos verbos apresentam o que é feito em pesquisa e $42 \%$ apresentam o que é dito sobre pesquisa. Observa-se que, nos resultados de Thomas e Hawes, 52\% de todos os verbos representam atividades da categoria Mundo Real/Experimento e $39 \%$ dos verbos representam a categoria Discurso. Portanto, os artigos médicos revelam uma tendência a dar mais espaço à própria pesquisa, ao passo que nos artigos em estudos organizacionais prevalece um espaço quase igualmente dividido entre a pesquisa em si e o discurso sobre a pesquisa. A lista dos 10 verbos mais usados nos artigos encontra-se na Tabela 3. 
Tabela 3 - Dez verbos mais usados na amostra

\begin{tabular}{|l|c|l|}
\hline \multicolumn{1}{|c|}{ Verbo } & Freqüência & \multicolumn{1}{c|}{ Categoria } \\
\hline Afirmar & 16 & Discurso \\
\hline Sugerir & 12 & Discurso \\
\hline Ressalta & 11 & Discurso \\
\hline Apresentar & 10 & Discurso \\
\hline Realizar & 9 & Mundo real \\
\hline Dizer & 9 & Discurso \\
\hline Considerar & 9 & Cognição \\
\hline Propor & 8 & Discurso \\
\hline Definir & 7 & Mundo real \\
\hline Argumentar & 6 & Discurso \\
\hline
\end{tabular}

Somente dois verbos ("realizar" e "definir") são usados freqüentemente para mencionar os procedimentos de pesquisa (Mundo Real/Experimento). Em contraste, sete dos verbos mais usados são da categoria Discurso. Esses autores, ao que parece, preferem falar menos da fase do experimento e fazer um esforço retórico considerável para apresentar discussões sobre a atividade de pesquisa, por exemplo, sobre hipóteses, argumentos e conclusões, deles mesmos e de outros pesquisadores.

A forte presença dos verbos de Discurso merece um exame mais detalhado. Entre os verbos nessa categoria encontram-se alguns sinais das preferências e práticas desses autores brasileiros. A Tabela 4, a seguir, apresenta verbos de Discurso encontrados na amostra do presente trabalho. A sub-categoria Restrição inclui os verbos que são usados para mitigar as propostas dos autores, ou sugerir a necessidade de pesquisa adicional, por exemplo, "alerta" e "limita-se". A sub-categoria Proposta inclui verbos que denotam propostas preliminares ou hipóteses a serem testadas ou, por outro lado, resultados de experimentos. Exemplos de verbos de Proposta são; "indica", "propõe", "sugere" e "apresenta". A terceira sub-categoria, Certeza, abriga os verbos de reportagem que se associam às afirmações mais conclusivas e definitivas. Essa sub-categoria sub-divide-se novamente, para aparecer a distinção entre o tipo Informe/Relato e o tipo Argumento. O primeiro sub-tipo de verbo passa a informação de modo neutro, sem implicar a (in)certeza da verdade da informação; são os verbos que não implicam a interpretação do autor, por exemplo, "diz", "ressalta", "discute", "exemplifica". O segundo sub-tipo de verbo, o de Argumento, dá o apoio argumentativo do qual o autor precisa. Ao interpretat o status da informação reportada, o autor adota uma posição perante a informação e, assim, mostra sua voz. De acordo com Thomas e Hawes (1994), em geral, esse posicionamento demonstra que o autor apoia a idéia ou proposta de um outro autor. Exemplos desse verbo, encontrados na amostra, são: "argumenta", "concorda", "critica", defende-se", "opõe-se". 
Entre os verbos listados na Tabela 3, um deles merece atenção. "Argumentar" aparece seis vezes e é o único verbo de sua categoria de verbo argumentativo que é destacado.

A Tabela 4, a seguir, apresenta verbos de discurso encontrados na amostra do presente trabalho.

Tabela 4 - Verbos de reportagem com função de discurso

\begin{tabular}{|l|r|r|r|r|r|r|r|r|}
\hline \multirow{2}{*}{ Discurso } & \multicolumn{2}{|l|}{ Restrição } & \multicolumn{2}{l|}{ Proposta } & \multicolumn{2}{l|}{ Certeza } & \multicolumn{2}{l|}{ TOTAIS } \\
\cline { 2 - 9 } & \multicolumn{1}{|l|}{$\mathrm{N}^{\mathrm{o}}$ abs. } & $\%$ & $\mathrm{~N}^{\mathrm{o}}$ abs. & $\%$ & $\mathrm{~N}^{\mathrm{o}}$ abs. & $\%$ & $\mathrm{~N}^{\mathrm{o}}$ abs. & $\%$ \\
\hline Verbos & 4 & 9 & 5 & 11 & 37 & 80 & 46 & 100 \\
\hline Ocorrências & 7 & 4 & 34 & 22 & 115 & 74 & 156 & 100 \\
\hline
\end{tabular}

Nos artigos em estudos organizacionais aqui analisados, é de notar que, na categoria Certeza, os verbos de Informar/Relato ocorrem muito mais freqüentemente (78\%) do que os verbos de Argumento (22\%). Portanto, na amostra do presente trabalho os verbos de argumentação representam uma parcela discreta entre verbos usados para discursar sobre pesquisa e pesquisadores, o que sugere que a postura argumentativa, que implica crítica e confronto, tem pouca preferência entre os autores brasileiros da amostra. Poderia ser perguntado se este fato revela algum traço cultural dos autores brasileiros, em relação à sua preferência por não concordar com, ou desafiar outros pesquisadores.

A tendência de uso do verbo argumentativo está relacionada, na amostra, à nacionalidade do autor citado. Em um exame mais detalhado da ocorrência do verbo de discurso, a contagem de verbos usados quando autores citam outros autores brasileiros revela que os argumentativos representam apenas $14 \%$ dos verbos nessas categorias. Entretanto, a soma total mostra que pesquisadores brasileiros são citados mais freqüentemente por meio de verbos de discurso do que autores não-brasileiros. Esse resultado sugere que autores brasileiros tendem a usar citações na função de Discurso, mais do que na função de atividades de pesquisa. (Mundo Real). Por fim, os brasileiros tendem a não privilegiar uma instância argumentativa ou a apresentar outros pesquisadores brasileiros de forma não crítica.

Por outro lado, autores brasileiros usam todos os tipos de verbos de reportagem mais freqüentemente quando apresentam pesquisadores estrangeiros do que quando citam outros brasileiros. A grande maioria dos verbos citados é usada para não-brasileiros. Foi possível identificar que 74\% dos verbos sobre atividades de pesquisa (Mundo Real), 75\% dos verbos de Discurso e $90 \%$ dos verbos de Cognição estão presentes em citações de não-brasileiros. Esses dados sugerem um destaque textual para aquilo que o pesquisador estrangeiro, e principalmente o anglo-americano, está fazendo e dizendo e sugerem também uma gama de opções mais vasta para apresentar a posição de autores face ao status da informação. 
Conforme mencionado, deve-se ter reservas ao se comparar os textos de Thomas e Hawes com os examinados no presente trabalho. Entretanto, uma conclusão desses autores ainda merece ser enfatizada por esclarecer como uma escolha lingüística pode refletir a preferência dos autores. Thomas e Hawes verificaram que diferentes tipos de verbos desempenham certas funções nas reportagens. Entre suas descobertas encontra-se o fato de que os verbos de Cognição mostram uma visão de consenso entre cientistas. Assim, um escritor sinaliza com expressões do tipo "um grande número de pesquisadores vêem o assunto" ou "o que eles acreditam do assunto". Expressões como essas mostram um apoio geral às idéias da comunidade científica e que pode servir de base para outros estudos posteriores (Thomas e Hawes 1994). Parece pertinente perguntar se os autores brasileiros usam verbos de Cognição da mesma forma. Descobrimos que o verbo de Cognição nesta amostra não tem a mesma função, pois é usado mais comumente em referências a alguns autores em particular. As únicas exceções em 26 ocorrências deste tipo de verbo de reportagem são "considerar" (que aparece três vezes nessa função) e "calcular" (uma vez). Assim, os autores brasileiros examinados não demonstram uma visão de como os pesquisadores coletivamente vêem os temas em suas áreas de estudo. Pode-se sugerir uma interpretação para esta tendência: os brasileiros optam por seguir uma linha quase definida por somente um autor.

\section{Para concluir}

Foi examinado neste trabalho como autores brasileiros utilizam suas informações sobre outros textos e sobre outros pesquisadores, no sentido de construir uma visão sobre o ambiente das organizações. Da análise da forma das citações, foi verificado que esses autores dão tanta importância às atividades de pesquisa (forma não-integral) quanto aos pesquisadores que eles citam (forma integral). Porém, uma descoberta significativa é que a maioria dos pesquisadores que são destacados nas citações são não-brasileiros e, quase sempre, angloamericanos. Quando os brasileiros citam a si mesmos eles usam quase sempre a forma entre parênteses, que os coloca em posição mais discreta. Assim, os pesquisadores não-brasileiros, como os americanos, por exemplo, estão mais em evidência nos textos examinados do que os brasileiros. É, também, significativo que, em termos de citação, é dado maior destaque à atividade de pesquisa, aos modelos, conceitos e métodos associados com o trabalho acadêmico realizado fora do Brasil, duas vezes mais freqüentemente do que o que é feito no país. Uma outra observação sobre a escolha de verbos de reportagem é o número relativamente pequeno de vezes em que verbos argumentativos são usados. Essa descoberta pode sugerir que o escritor estaria evitando comportamento argumentativo e, assim, evitando desafiar pesquisadores de prestígio e modelos universalmente aceitos.

O exame dos verbos de reportagem também mostrou uma grande visibilidade de atividades não-brasileiras. Há muito mais verbos usados em reportagem para pesquisadores estrangeiros, notadamente os anglo-americanos, do que para os brasileiros. Sendo mais explícitos sobre como os estrangeiros fazem ou dizem, estão os autores brasileiros reconhecendo o prestígio dos pesquisadores de outros países, e principalmente os americanos? Uma outra explicação seria que, por causa de sua formação educacional e de pesquisa, os autores brasileiros talvez tenham lido muito a literatura dos Estados Unidos e talvez estejam mais entrosados com os assuntos e debates em andamento naquele país. Esses autores, provavelmente, estão menos antenados com as pesquisas em andamento no Brasil, que discutem a realidade das organizações daqui. Isto talvez faça com que os autores sintam-se 
mais à vontade para importar modelos do exterior, considerando que eles estão conscientes do volume e da densidade da pesquisa que produziu aqueles modelos.

As preocupações levantadas por vários pesquisadores encontram suporte na análise usada neste artigo. Nos artigos examinados sobre estudos organizacionais, o padrão de citações a pesquisadores brasileiros revelam uma exposição limitada desses pesquisadores e corroboram a visão da atividade relativamente pequena de pesquisa sobre empresas brasileiras. Ainda, com a grande exposição que é dada às pesquisas e aos pesquisadores não-brasileiros e por causa de um estilo que esses autores brasileiros assumem, ou seja, de não contestar, pode-se dizer que eles aceitam os modelos importados de pesquisa.

Resumindo, autores brasileiros:

$\checkmark$ preferem destacar o pesquisador citado, em detrimento de conceitos, teorias, métodos e conclusões de pesquisa;

preferem não explicitar sua opinião sobre o quê ou quem está sendo citado;

$\checkmark$ preferem a forma não-integral para a auto-citação, talvez com o objetivo de mitigar a atenção para seu próprio trabalho de pesquisa;

são mais explícitos sobre o que autores estrangeiros, dentre os quais destacam-se os angloamericanos, dizem ou fazem;

tendem a não privilegiar instância argumentativa, o que pode explicar a facilidade com que importam modelos gerados em outras culturas, sobretudo a anglo-americana;

$\checkmark$ parecem depender de poucas fontes de informações, já que, ao referir-se a um assunto, tendem a não apresentar vários pesquisadores que a ele tenham se dedicado, preferindo optar por seguir uma linha, praticamente, definida por um único autor;

fazem pouca exposição de pesquisadores brasileiros;

dão mais destaque ao trabalho científico produzido fora do Brasil, especialmente aquele produzido nos Estados Unidos.

O problema aqui enfatizado é que modelos estão sendo transportados de um contexto e cultura para outro e a especificidade da cultura brasileira necessita um modelo próprio. A conseqüência provável de basear-se em modelos importados poderia ser que áreas de estudos como os organizacionais simplesmente não estão sendo desenvolvidas de forma apropriada para produzir informação que reflita o ambiente local da atividade científica. O que é importado deve ser visto criticamente, com uma grande dose de informações da sociedade brasileira. Tais informações podem depender de um cuidadoso exame do que pesquisadores brasileiros dizem e fazem. O problema agrava-se quando, além de basear-se, prioritariamente, em fontes anglo-americanas, o autor brasileiro não só limita-se em seu artigo a poucos desses autores, como assume comportamento de não polemização. 
Dado que citações explicitam o que foi dito ou feito por quem, sinalizando a posição do escritor face ao que foi dito ou feito, uma base intertextual em pesquisa desenvolvida no Brasil e apresentada nos textos dos pesquisadores pode servir ao propósito de levantar e analisar o jeito brasileiro de publicar em estudos organizacionais.

\section{Bibliografia}

AMSTERDAMSKA, O. e LEYDESDORFF, L. Citations: indicators of significance? Scientometrics, 115, 5-6:449-471, 1989.

BERNARDES, M. E. B. Learning organization em empresa brasileira: um estudo de caso, Anais do ENANPAD 99. Foz de Iguaçu, 1999.

BERTERO, C. O. e KEINERT, T. M. M. A evolução da análise organizacional no Brasil (1961-93). Revista de Administração de Empresas. São Paulo: Fundação Getulio Vargas, v. 36, n. 3, 1994.

BERTERO, C. O., CALDAS, M.P. e WOODJr,T. Produção científica em administração de empresas: provocações, insinuações e contribuições para um debate local. Revista de Administração Contemporânea. ANPAD, v. 3, n. 1, 1999.

BETHLEM, A. S. Gerência à brasileira. São Paulo: McGraw-Hill, 1989.

CARVALHO, Jr., D. e VERGARA, S. C. Refletindo sobre as possíveis consequiências de análise organizacional apoiada em referências estrangeiras. Revista de Administração Pública. Rio de Janeiro: Fundação Getulio Vargas, 1996, v.30, n. 61996.

CRONIN, B. The need for a theory of citing. Journal of Documentation, v. 37, n.1 1981.

ENGWALL, L. Asterix in Disneyland: business scholars from France on the world scene. Draft of paper, 1996.

LIMA, J.B. Pesquisa qualitativa e qualidade na produção científica em administração de empresas, Anais do ENANPAD 99. Foz de Iguaçu, 1999.

SWALES, J. M. Genre Analysis: English in Academic and Research Settings. Cambridge: Cambridge University Press, 1990.

THOMAS, S. e HAWES, T. P. Reporting verbs in medical journal articles. English for Specific Purposes, v. 13, n. 2, 1994.

VERGARA, S. V. e CARVALHO, Jr., D. Nacionalidade dos autores referenciados na literatura brasileira sobre organizações" Revista Brasileira de Administração Contemporânea, 1995.

VERGARA, S.V. e PINTO, Mario C.S. Nacionalidade das referências teóricas em análise organizacional. $1^{\mathrm{O}}$ Encontro de Estudos Organizacionais. Anais. Curitiba, 2000. 